\title{
Risk based analysis of RHPP penstock structural integrity
}

\author{
Snežana Kirin, Lazar Jeremić \\ Innovation Center of the Faculty of Mechanical Engineering, Belgrade, Kraljice Marije 16, Serbia \\ snezanakirin@yahoo.com,laki991@hotmail.com
}

\author{
Aleksandar Sedmak \\ University of Belgrade, Faculty of Mechanical Engineering, Kraljice Marije 16, 11020 Belgrade 35, Serbia \\ asedmak@mas.bg.ac.rs
}

Igor Martić, Simon Sedmak, Ivana Vučetić

Innovation Center of the Faculty of Mechanical Engineering, Belgrade, Kraljice Marije 16, Serbia

simonsedmak@yahoo.com

Tamara Golubović

Innovation Center of the Faculty of Technology and Metallurgy, Belgrade, Karnegijeva 4, Serbia

simonsedmak@hotmail.com

\begin{abstract}
Risk based analysis of reverse hydro power plant penstock structural integrity is performed using fracture mechanics parameters. To assess its structural integrity, extensive testing of the full-scale prototype had been performed, including hydrostatic over-pressurizing, during the design phase. More recently, the Failure Assessment Diagram has been used to evaluate probability, whereas phenomenological analysis has been used to estimate consequence, in the scope of common risk estimation. It is shown that over-pressuring has potential detrimental effect on pipeline safety, i.e. structural integrity.
\end{abstract}

KEYWORDS. Over-pressure; Pipeline; Structural integrity; Risk matrix.

\section{OPEN ACCESS}

Citation: Kirin, S., Jeremić, L., Sedmak, A., Martić, I., Sedmak, S., Vučetić, I., Golubović, T., Risk based analysis of RHPP penstock structural integrity, Frattura ed Integrità Strutturale, 53 (2020) 345-352.

Received: 12.05 .2020

Accepted: 31.05 .2020

Published: 01.07.2020

Copyright: (C) 2020 This is an open access article under the terms of the CC-BY 4.0, which permits unrestricted use, distribution, and reproduction in any medium, provided the original author and source are credited.

\section{INTRODUCTION}

eversible Hydro Power Plant (RHPP) "Bajina Basta" is in operation since 1982, [1, 2]. Taking into account that the failure of its most critical part, the penstock, Fig. 1, would cause water overflow of the surge hub in the surrounding area, and the collapse of the entire plant, it is clear that special attention is still needed to prove its structural integrity. 
This is especially important when it comes to the proof testing, now scheduled for 2022, since it has been shown that overpressure can cause significant damage and bring no benefit, [3]. Therefore, the basic aim of this paper is to make risk based analysis of the penstock structural integrity with focus of overpressure effect. Toward this aim, a simple engineering tool will be used to estimate probability, [4-10], and simple reasoning will be used to estimate consequence, [7, 11], so that risk will be evaluated as the product of these two. This approach is also adopted in the scope of ESIS TC12 activities, [12].

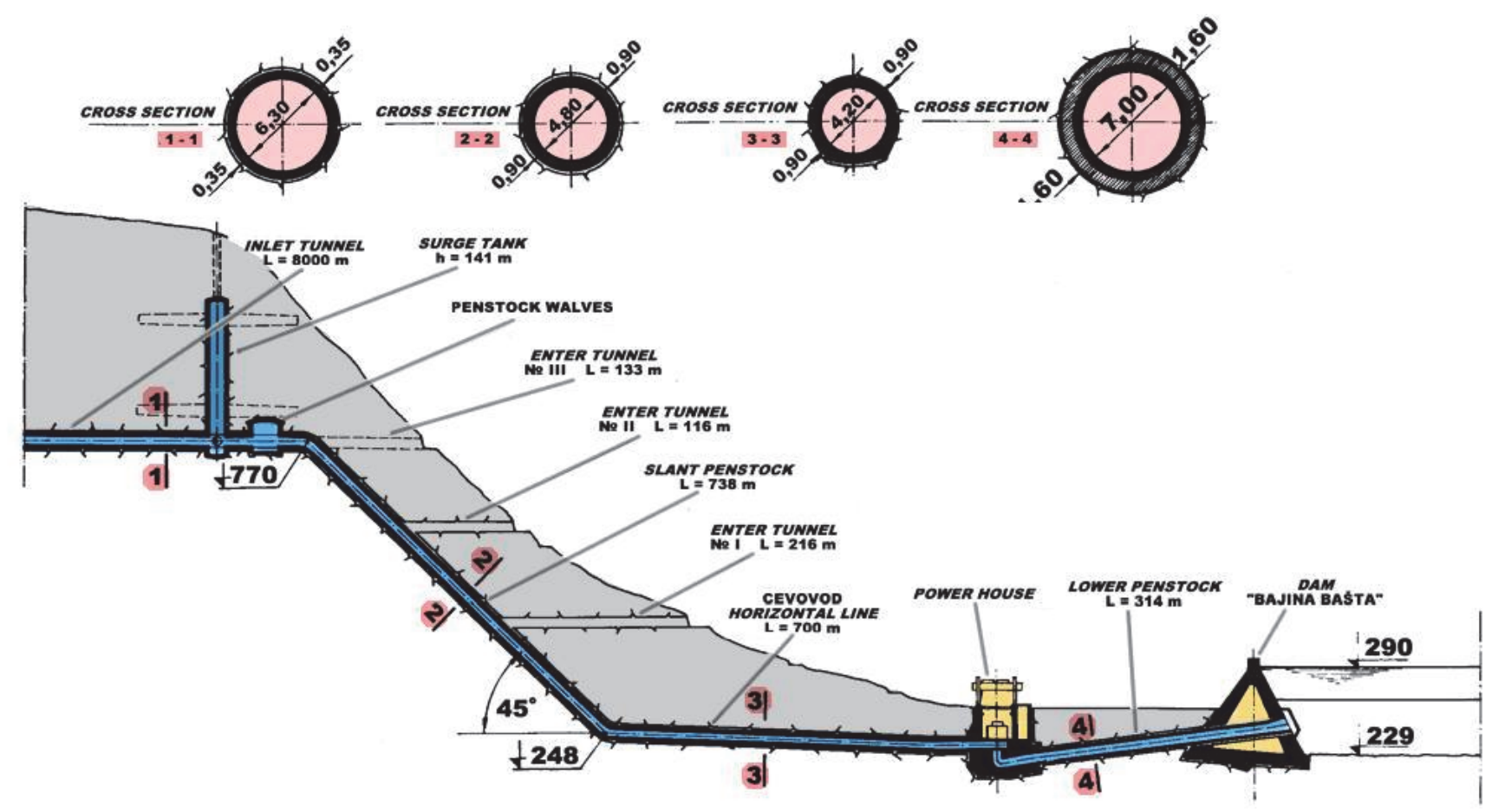

Figure 1: Disposition of penstock (upper and lower pipeline) "Bajina Bašta".
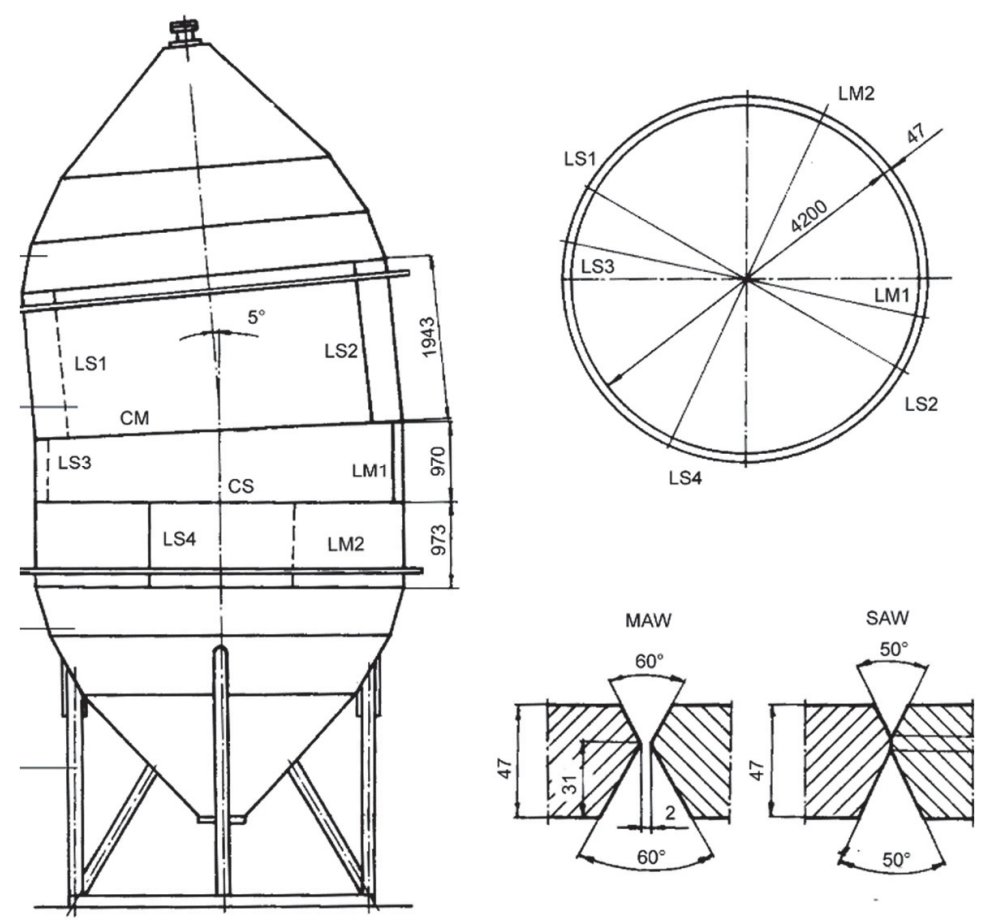

Figure 2: The full-scale model: L-Longitudinal, C-Circular; MAW - shielded manual arc welding; SAW-submerged arc welding 


\section{RHPP BAJINA BASTA - PENSTOCK DESIGN AND TESTING}

$\mathrm{H}$ aving in mind the importance of the penstock, special design procedure has been used, combined with extensive testing of the full-scale prototype, Fig. 2, including static, dynamic and fracture mechanics testing, based on the request to construct only one pipeline, made of steel with yield strength significantly higher than for the common structural steels. Therefore, SUMITEN HT80 was chosen, quenched and tempered weldable High Strength Low Alloyed (HSLA) steel, with nominal Yield Strength (YS) above $700 \mathrm{MPa}$, and Tensile Strength (TS) cca $800 \mathrm{MPa}$. Anyhow, welded joints made of such steels are well known for their susceptibility to cracking, making three stages hydrostatic proof testing of the model inevitable:

1. Loading from 0 to $3 \mathrm{MPa}$ to check the measuring system.

2. Loading from 0 to $9.02 \mathrm{MPa}$, to reach the service stress.

3. Overloading $(33.3 \%)$ from 0 to $12.05 \mathrm{MPa}$, as required by the regulation.

Full-scale model strains were measured by Strain Gages (SG) and Moiré grids, as described in details in [1,2]. In the base metal (BM) response was dominantly elastic, whereas plastic strain (0,24\%) was registered in welded joint LS1 (SG2, SG34), indicating non-uniform, even strange behavior due to stress concentration and weld mismatching, as shown in [4].

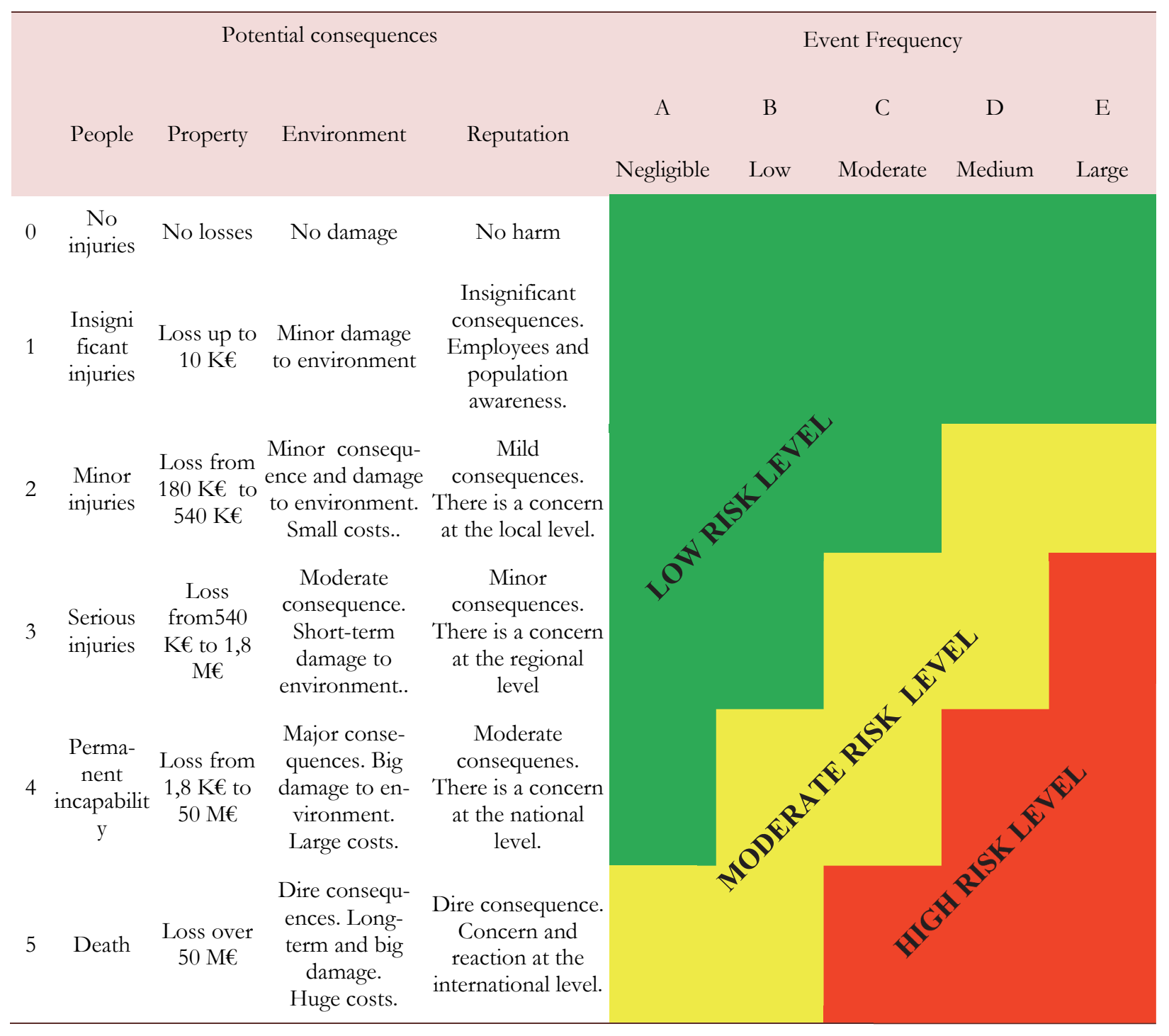

Table 1: Descriptive risk matrix, taken from [11]. 


\section{RISK MATRIX}

$\mathrm{W}$

hen observing the risk, possible consequences for the people, property, environment and reputation of the company should be considered. In the suggested model, we proposed a combination of qualitative and quantitative approach to the assessment of potential consequences, as given in Tab. 1 in the form of risk matrix, $[7,11]$. Other aspects of risk based structural integrity assessment is given in [3-11].

As already shown in the case of pressure vessels that would cause air strike and significant damage, probably with fatalities, $[7,11]$, this is the case also with eventual penstock failure. The indirect damage would be the total stoppage of a reversible hydroelectric power plant for long period of time. Therefore, potential consequence in the case of penstock failure is certainly the highest one, category 5 , since it would cause the collapse of the entire power plant.

Anyhow, the approach adopted here will not consider event frequency when probability is evaluated, since it has no relevance to the case considered. Instead, engineering approach will be applied, based on fracture mechanics concept, i.e. Failure Assessment Diagram (FAD), as described for different applications in [3-11].

\section{FAILURE ASSESSMENT DiAgRAM APPLICATION}

$\mathrm{F}$ ailure Assessment Diagram, in its simplest form, i.e. level 1 as shown Fig. 3, enables one of the most efficient ways to assess structural integrity of a cracked component made of elastic-plastic material, such as HSLA steel. Basically, FAD indicates safe and unsafe position of a point corresponding to a given stress state for a cracked component, divided by so-called limit curve, Fig. 3:

$$
K_{r}=S_{r}\left[\frac{8}{\pi^{2}} \ln \sec \left(\frac{\pi}{2} S_{r}\right)\right]^{1 / 2}
$$

where $S_{r}=S_{n} / S_{c}$ and $K_{r}=K_{I} / K_{I c}, S_{n}$ stands for stress in net cross section, $S_{c}$ for the critical stress (Yield Strenght, Tensile Strength or any value in-between), $K_{I}$ for the stress intensity factor and $K_{I c}$ for its critical value, i.e. fracture toughness.

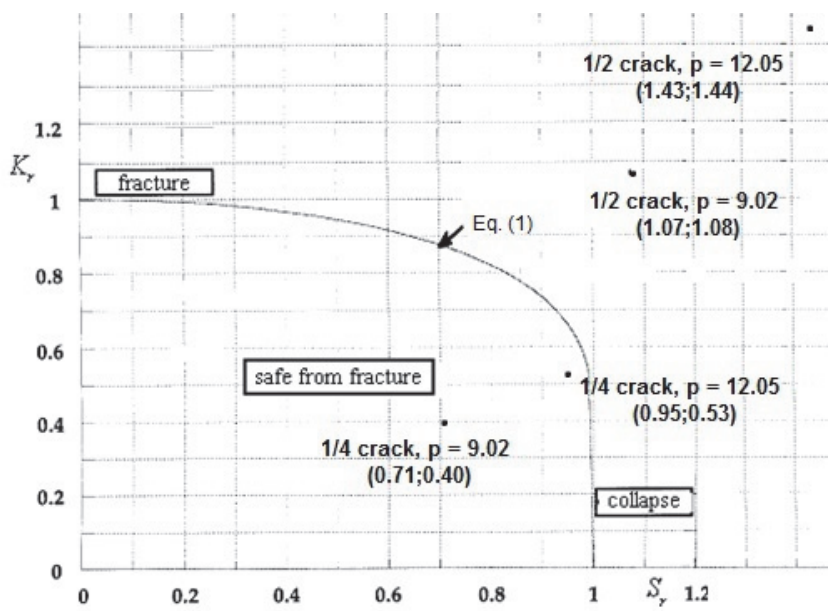

Figure 3: Failure Assessment Diagram, including assessment points for edge cracks.

Using experience and results of previous testing of the prototype, [1,2], two axial surface cracks are analysed here, both with length $90 \mathrm{~mm}$, one with depth $11.75 \mathrm{~mm}(1 / 4$ of penstock thickness, $47 \mathrm{~mm})$, and the other one with depth $23.5 \mathrm{~mm}(1 / 2$ of penstock thickness). Two loading cases are analysed, one being 9.02 MPa (design pressure), and the other one $12.05 \mathrm{MPa}$ (hydrostatic proof testing pressure, $33.3 \%$ higher). Conservative assumption would be to consider cross-section as being just where the crack is, i.e. $90 \mathrm{~mm}$ wide and $47 \mathrm{~mm}$ deep (minus the crack depths), i.e. $3 / 4$ or $1 / 2$ of the original value, and use formulas for an edge crack, whereas $\mathrm{S}_{\mathrm{c}}$ is taken as average value of YS and TS, i.e. $750 \mathrm{MPa}$ :

- $S_{n}$ is taken as $536 \mathrm{MPa}$, for „, $1 / 4^{4}$ crack and $804 \mathrm{MPa}$ for, $1 / 2$ “ crack, with remote stress $402 \mathrm{MPa}$ for $\mathrm{p}=9.02 \mathrm{MPa}$ and $536 \mathrm{MPa}$ for $\mathrm{p}=12.05 \mathrm{MPa}$.

- $S_{r}=S_{n} / S_{c}=536 / 750=\mathbf{0 . 7 1}$ for $\mathrm{p}=9.02 \mathrm{MPa}, \mathbf{0 . 9 5}$ for $\mathrm{p}=12.05 \mathrm{MPa}$ and „1/4“ crack. 
- $S_{r}=S_{n} / S_{c}=804 / 750=1.07$ for $\mathrm{p}=12.05 \mathrm{MPa}, \mathbf{1 . 4 3}$ for $\mathrm{p}=12.05 \mathrm{MPa}$ and „1/2“ crack.

- $K_{I}=1.39(\mathrm{pR} / \mathrm{t}) \sqrt{ }_{\pi \mathrm{a}}=1.39 \cdot 402 \cdot \sqrt{ } \pi \cdot 11.75=3402 \mathrm{MPa} \sqrt{\mathrm{mm}}$ for $\mathrm{p}=9.02 \mathrm{MPa}$ and $\mathrm{a} / \mathrm{t}=0.25$ or $4536 \mathrm{MPa} \sqrt{\mathrm{mm}}$ for $\mathrm{p}=12.05$ $\mathrm{MPa}$ and $\mathrm{a} / \mathrm{t}=0.25$.

- $K_{I}=2.71(\mathrm{pR} / \mathrm{t}) \sqrt{ }_{\pi \mathrm{a}}=2.71 \cdot 402 \cdot \sqrt{ } \pi \cdot 23.5=\mathbf{9 3 8 0} \mathrm{MPa} \sqrt{\mathrm{mm}}$ for $\mathrm{p}=9.02 \mathrm{MPa}$ and $\mathrm{a} / \mathrm{t}=0.5$ or $12507 \mathrm{MPa} \sqrt{\mathrm{mm}}$ for $\mathrm{p}=12.05$ $\mathrm{MPa}$ and $\mathrm{a} / \mathrm{t}=0.5$.

- $K_{I c}=\sqrt{ }\left(\mathrm{E} J_{\mathrm{Ic}} /\left(1-\nu^{2}\right)=8548 \mathrm{MPa} \sqrt{\mathrm{mm}}_{\mathrm{J}} \mathrm{J}_{\mathrm{Ic}}=316.6 \mathrm{~N} / \mathrm{mm}[13]\right)$.

- $K_{r}=K_{I} / K_{I c}=3402 / 8548=\mathbf{0 . 4 0} \quad(\mathrm{p}=\mathbf{9 . 0 2}, 1 / 4), 4536 / 8548=\mathbf{0 . 5 3} \quad(\mathrm{p}=\mathbf{1 2 . 0 5}, \mathbf{1 / 4}), \quad 9380 / 8548=\mathbf{1 . 0 8} \quad(\mathrm{p}=\mathbf{9 . 0 2}, 1 / 4)$, $12507 / 8548=1.44(\mathrm{p}=12.05,1 / 2)$.

Therefore, the FAD coordinates obtained for cracks treated as through thickness cracks with depths being $1 / 4$ and $1 / 2$ half of thickness, are as follows, Fig. 1:

For $1 / 4$ crack, $\mathrm{p}=9.02(0.71,0.40), \mathrm{p}=12.05(0.95,0.53)$.

For $1 / 2$ crack, $\mathrm{p}=9.02(1.07,1.08), \mathrm{p}=12.05(1.43,1.44)$.

Clearly, this is overconservative estimation since both material and crack geometry are presented in conservative way. Anyhow, even this simple analysis indicates detrimental effect of over-pressurizing, since the points corresponding with it are way out of the safe region ( $1 / 2$ crack), or very close to the limit curve $(1 / 4$ crack), Fig. 3.

Less conservative assumption would be to consider cracks as they are, i.e. treat them as surface cracks. In that case reduction of cross-section is negligible, so $\mathrm{S}_{\mathrm{n}}$ and $\mathrm{S}_{\mathrm{r}}$ are calculated as follows:

- $S_{n}=\mathrm{pR} / \mathrm{t}=9.02 \times 2.1 / 0.047=402 \mathrm{MPa}$,

- $S_{n}=\mathrm{pR} / \mathrm{t}=12.05 \times 2.1 / 0.047=536 \mathrm{MPa}$.

- $S_{r}=\mathrm{Sn} / \mathrm{Sc}=402 / 750=0.54$

- $S_{r}=S_{n} / S_{c}=538 / 750=0.72$

Stress intensity factor for surface edge crack in a plate can be evaluated using the following procedure from [14]. Plate is taken as better approximation than thin cylinder, since the ratio $B / r_{i}$ is just $47 / 2100=0.023$, i.e. much closer to 0 than to 0.1 , which is the lowest value for cylinders in [14].

Geometry parameters $\mathrm{F}$ and $\mathrm{Q}$ are calculated for tensile plate with a surface crack $(\mathrm{a} / 2 \mathrm{c}=0.13$ for $1 / 4 \mathrm{crack}$ and $\leq 1)$ at the point of maximum stress intensity factor $(\varphi=900)$ as follows:

$$
\begin{aligned}
& Q=1+1.464\left(\frac{c}{a}\right)^{1.65}=1.08 \text { for } 1 / 4 \text { crack and } 1.22 \text { and for } 1 / 2 \text { crack } \\
& F=\left[M_{1}+M_{2}\left(\frac{a}{t}\right)^{2}+M_{3}\left(\frac{a}{t}\right)^{4}\right] g f_{\varphi} f_{w}=1.102 \text { for } 1 / 4 \text { crack and } 1.033 \text { and for } 1 / 2 \text { crack, } \\
& M_{1}=\left[1.13-0.09\left(\frac{c}{a}\right)\right]=1.106 \text { for } 1 / 4 \text { crack and } 1.108 \text { and for } 1 / 2 \text { crack } \\
& M_{2}=0.54+\frac{0.89}{1+a / c}=1.39 \text { for } 1 / 4 \text { crack and } 0.7 \text { and for } 1 / 2 \text { crack, } \\
& M_{3}=0.5-\frac{1}{0.65+\frac{a}{c}}+14\left(1-\frac{a}{c}\right)^{24}=-0.589 \text { for } 1 / 4 \text { crack and }-0.355 \text { and for } 1 / 2 \text { crack, } \\
& g=1+\left[0.08+0.15\left(\frac{c}{t}\right)^{2}\right](1-\cos \varphi)^{3}=1 \\
& f_{\varphi}=\left[\left(\frac{c}{a}\right)^{2} \sin ^{2} \varphi+\cos ^{2} \varphi\right]^{\frac{1}{4}}=1, f_{w}=\left[\sec \left(\frac{\pi c}{2 W} \sqrt{\frac{a}{t}}\right)\right]^{\frac{1}{2}}=1
\end{aligned}
$$


Now, for $\mathrm{a} / \mathrm{t}=0.25$ one can calculate $K_{I}=2837 \mathrm{MPa} \sqrt{\mathrm{mm}}$ for $\mathrm{p}=9.02 \mathrm{MPa}$ and $3777 \mathrm{MPa} \sqrt{\mathrm{mm}}$ for $\mathrm{p}=12.05 \mathrm{MPa}$, whereas for $\mathrm{a} / \mathrm{t}=0.5 K_{I}=4012 \mathrm{MPa} \sqrt{\mathrm{mm}}$ for $\mathrm{p}=9.02 \mathrm{MPa}$ and $5341 \mathrm{MPa} \sqrt{\mathrm{mm}}$ for $\mathrm{p}=12.05 \mathrm{MPa}$. Finally, assessment points coordinates in FAD are, Fig. 4:

For $1 / 4$ crack, $\mathrm{p}=9.02(0.54,0.33), \mathrm{p}=12.05(0.54,0.46)$. Corresponding probablities are 0.58 and 0.62 .

For $1 / 2$ crack, $\mathrm{p}=9.02(0.72,0.44), \mathrm{p}=12.05(0.72,0.62)$. Corresponding probablities are 0.75 and 0.82 .

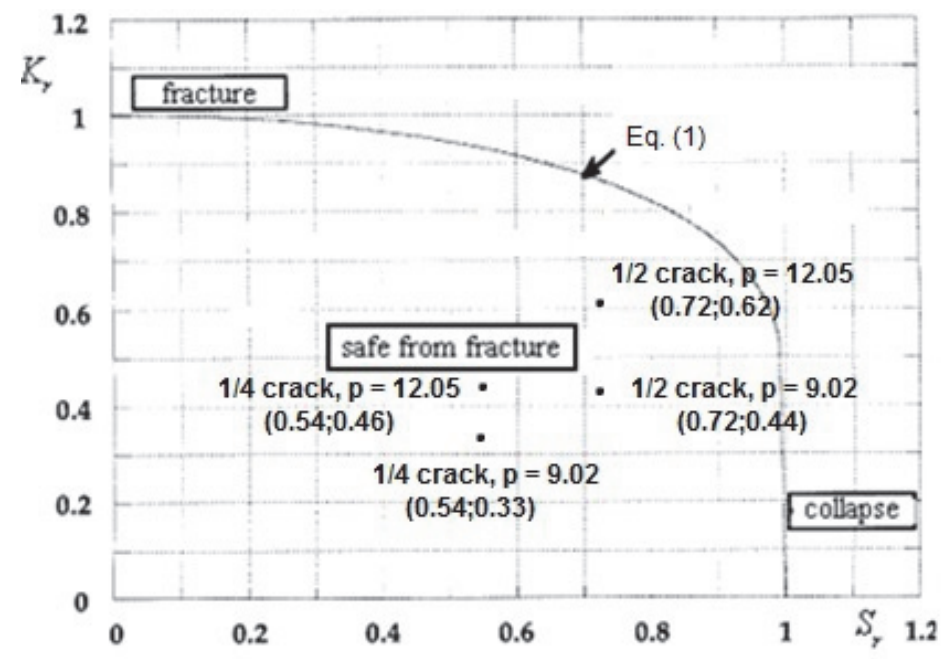

Figure 4: Failure Assessment Diagram, including assessment points for surface cracks

Now, one can get risk matrix in usual way, as presented in Tab. 2, indicating shift from high (0.58) to very high risk (0.62), for $1 / 4$ crack, or from very high (0.75) to extremely high risk (0.82) for $1 / 2$ crack.

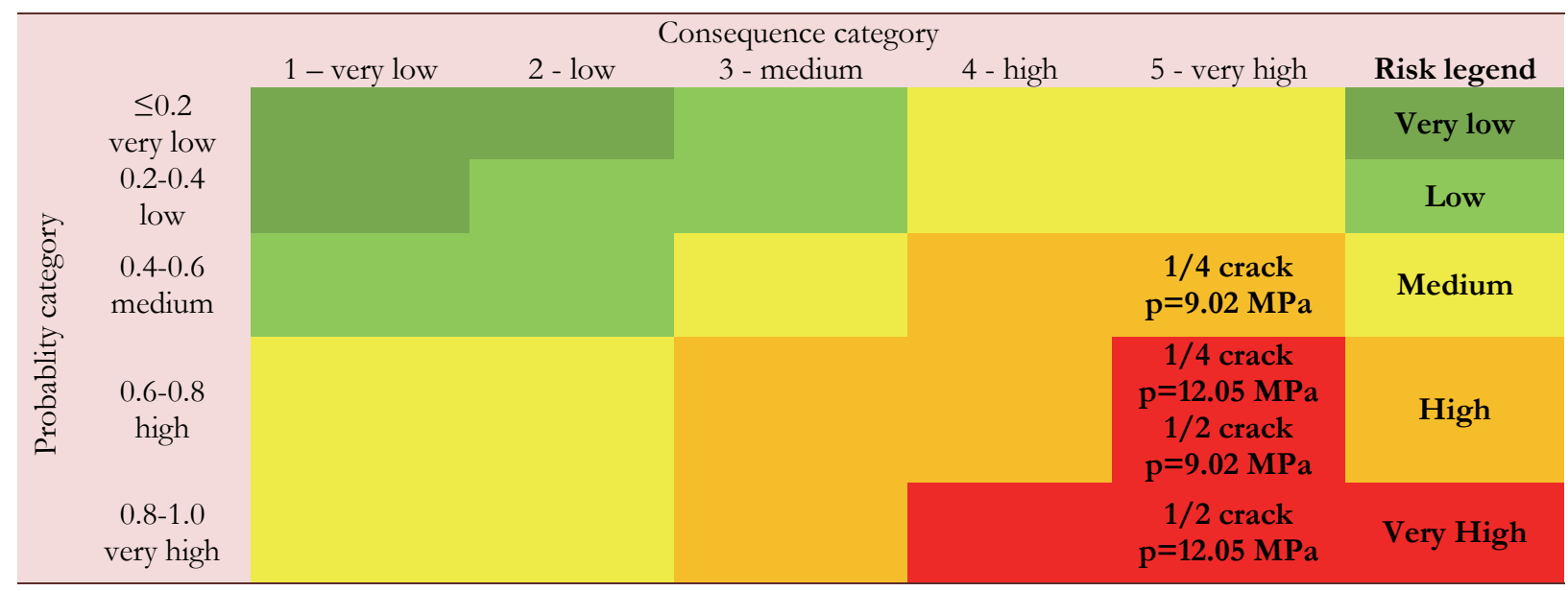

Table 2: Risk matrix for $1 / 4$ crack and $1 / 2$ crack, $\mathrm{p}=9.02 \mathrm{MPa}$ and $12.05 \mathrm{MPa}$.

\section{Discussion}

7 he approach so far presented is the simplest one which takes into account crack geometry and material behaviour. Being the simplest it is not the most accurate one, lacking precise stress distribution, especially in weld joint zones. Namely, as shown previously, [1,2], stress concentration can cause local plastic deformation in welded joints made by SAW, in the case of overpressure, since they have the lowest YS (687 MPa). To take into account such effects, more sophisticated approach is needed, e.g. Japp vs. J-R curve analysis, based on more complex analytical solutions for J, [1,2]. Here, such an analysis is briefly presented, as shown in Fig. 5. Corresponding critical values $(0.91 \cdot Y S$ for WM and $0.92 \cdot Y S$ for $\mathrm{BM}$ in the case of $1 / 4$ crack, or $0.82 \cdot \mathrm{YS}$ for WM and $0.85 \cdot \mathrm{YS}$ for BM in the case of $1 / 2$ crack, can be taken as inverse of 
probability, but this is beyond the scope of this approach since its basic advantage, simplicity, would be lost. Anyhow, one can notice that overpressure in weld metal can reach the critical state, since only $563 \mathrm{MPa}$ would cause unstable crack growth in SAW weld metal with $1 / 2$ crack, whereas operating pressure would not jeopardize penstock integrity even in that case.

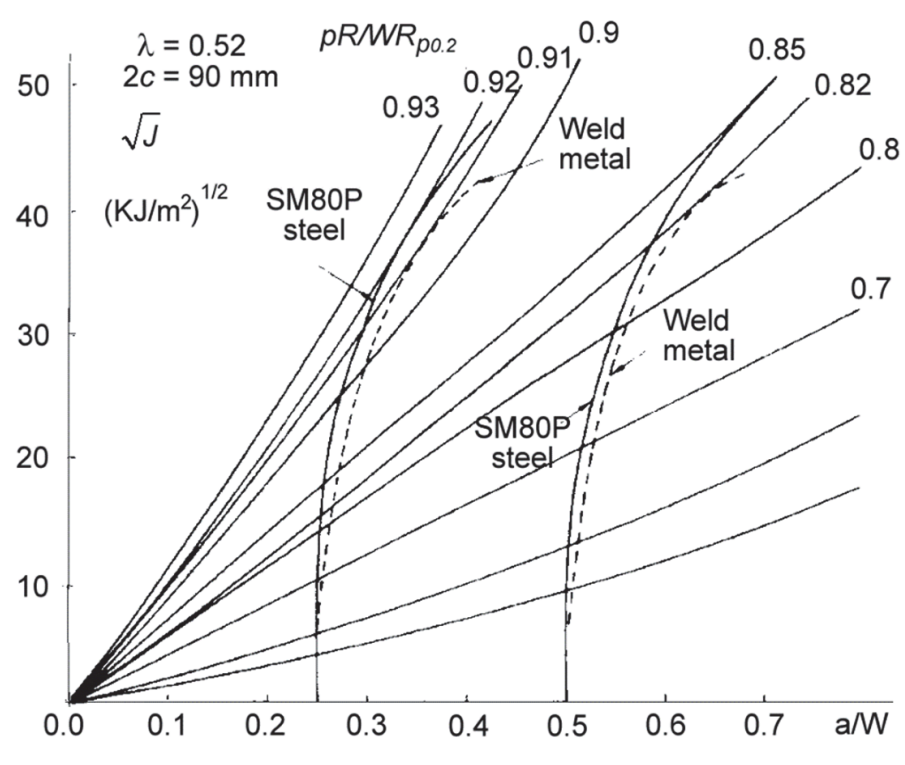

Figure 5: Crack driving force vs. J-R curves for BM and WM.

\section{CONCLUSIONS}

B. ased on the results shown here, one can conclude the following

- Risk based analysis using fracture mechanics parameters, as presented here, is efficient engineering method to assess structural integrity of a cracked component, especially if its geometry is relatively simple.

- Effect of over-pressure is detrimental from the point of view of structural integrity since it can cause unnecessary damage of welded joints, as the most crack sensitive regions. Both simple engineering method, as presented here, and previously performed more complex fracture mechanics analysis, lead to that conclusion.

\section{REFERENCES}

[1] Sedmak, S., Sedmak, A. (2005) Integrity of Penstock of Hydroelectric Power plant, Structural Integrity and Life 5, pp. $59-70$

[2] Sedmak, S., Sedmak, A. (1995). Experimental investigation into the operational safety of a welded penstock by a fracture mechanics approach, Fatigue and Fracture of Engineering Materials and Structures 18, pp. 527-538

[3] Martić, I., Sedmak, A., Mitrović, N., Sedmak, S., Vučetić, I. (2019). Effect of over-pressure on pipeline structural integrity, Technical Gazette, 26(3), pp. 852-855

[4] Golubović, T., Sedmak, A., Spasojević Brkić, V., Kirin, S., Rakonjac, I. (2018). Novel risk based assessment of pressure vessels integrity. Technical Gazette, 25(3), pp. 803-807.

[5] Sedmak, A., Algool, M., Kirin, S., Rakicevic, B., Bakic, R. (2016). Industrial safety of pressure vessels - Structural integrity point of view, Hemijska industrija, 70(6), pp .685-694

[6] Golubović, T., Sedmak, A., Spasojević Brkić, V., Kirin, S., Veg, E. (2018). Welded joints as critical regions in pressure vessels - case study of vinyl-chloride monomer storage tank, Hemijska Industrija, 72(4), pp. 177-182.

[7] Vučetić, I., Kirin, S., Sedmak, A., Golubović, T., Lazic, M. (2019). Risk management of a hydro power plant - fracture mechanics approach, Technical Gazette 26, pp. 428-432.

[8] Pilić, V., Mihajlović, V., Stanojević, P., Anđelković, A., Baloš, D. (2019). Application of innovative risk assessment methodology for damage mechanisms identification on part of amine regeneration unit, Structural Integrity and Life, 19(1), pp.29-35. 
[9] Pilić, V., Stanojević, P., Mihajlović, V., Baloš, D. (2019). Damage mechanism and barrier identification on hydrogen production unit using innovative methodology for risk assessment, Structural Integrity and Life, 19(2), pp.131-137.

[10] Zaidi, R., Sedmak, A., Kirin, S., Grbovic, A., Li, W., Lazic Vulicevic, L., Sarkocevic, Z. (2020). Risk assessment of oil drilling rig welded pipe based on structural integrity and life estimation, Engineering Failure Analysis, 112, 104508.

[11] Vučetić, I., Kirin, S., Vučetić, T., Golubović, T., Sedmak, A. Risk Analysis in the Case of Air Storage Tank Failure at RHPP Bajina Bašta, Structural Integrity and Life, 18 (1), pp. 3-6.

[12] Correia, J.A.F.O., De Jesus, A.M.P., Muniz-Calvente, M., Sedmak, A., Moskvichev, V., Calçada, R. (2019). The renewed TC12/ESIS technical committee - Risk analysis and safety of large structures and components (Editorial), Engineering Failure Analysis, 105, pp. 798-802.

[13] Petrovski, B. (1985). Determination of residual strength of pressure vessel with a surface crack (in Serbian), Ph.D. thesis, University of Belgrade.

[14] FITNET Fitness-for-service (FFS) Annex, (2008), 2, ISBN 978-3-940923-01-1. 